\title{
Glycemic control among children and adolescents with type 1 diabetes during COVID-19 pandemic in Egypt: a pilot study
}

\author{
Yasmine Ibrahim Elhenawy ${ }^{1} \cdot$ Khadiga Yehia Eltonbary $^{1}$
}

Received: 24 March 2021 / Accepted: 12 June 2021 / Published online: 9 July 2021

(c) Research Society for Study of Diabetes in India 2021

\begin{abstract}
Background The COVID-19 pandemic and the consequences of lockdown significantly impacted glycemic control.

Aim To evaluate the impact of the pandemic and lockdown on glycemic control among Egyptian children and adolescents with type 1 diabetes.

Methods Cross-sectional study conducted through an online questionnaire. The participants were patients with type 1 diabetes and/or their caregivers

Results A total of 115 valid responses to the questionnaire were received. During the lockdown, almost $64 \%$ of patients showed worsening of their HbA1C with significant increment of HbA1c after the lockdown $(\mathrm{p}<0.001)$. Synchronous simple telemedicine service was initiated through phone calls and social media applications, and $97 \%$ of the patients and their families were successfully able to continue follow-up. Almost $76 \%$ of the patients/caregivers showed moderate stress which was significantly correlated with $\mathrm{HbA1C}(\mathrm{p}<0.05)$. Fear of hospital admission and fear from shortage of medical supplies were the main COVID-19-related worries.

Conclusion The lockdown negatively impacted glycemic control and initiated a set of COVID-19 worries and stress among patients and their caregivers in Egypt. Telemedicine service, even simple tools, is effective and important for the continuity of care among patients. The limited availability and the fear of shortage of medical supply forced patients to ration glucose monitoring.
\end{abstract}

Keywords COVID-19 $\cdot$ Lockdown $\cdot$ Telemedicine $\cdot$ Type 1 diabetes

\section{Introduction}

On March 11, 2020, the coronavirus disease 2019 (COVID19) was declared as a global pandemic [1]. The pandemic significantly impacted all countries, creating heavy burdens and affecting different substructures of the country. Global measures were promptly initiated to limit spread of infection, and different countries announced a series of restrictions. On March 2020, Egypt imposed a series of nationwide lockdown to control the spread of infection $[1,2]$.

The burden of COVID-19 has been increasing continuously, and special concerns were linked to patients with chronic disorders like diabetes [3]. The implemented

Yasmine Ibrahim Elhenawy

dr_yasmi@yahoo.com

1 Pediatric and Adolescent Diabetes Unit (PADU), Department of Pediatrics, Faculty of Medicine, Ain Shams University, Cairo, Egypt restrictions and social distancing practices resulted in changes in daily routine with modifications of lifestyle and dietary habits [4]. It is expected that lockdown could initiate a series of challenges affecting continuity of medical care and availability of medical supplies, all of which may negatively impact the complex routine management of diabetes [3].

Although impact of lockdown on glycemic control among patients with type 1 diabetes has been reported in various studies [5-7], there is paucity of data addressing the impact of lockdown on management of children and adolescents with type 1 diabetes in developing countries with limited resources.

To the best of our knowledge, this is the first published study evaluating the impact of COVID-19 pandemic and lockdown on glycemic control among Egyptian children and adolescents with type 1 diabetes. The study also aimed to highlight and map factors associated with lockdown that could affect the overall glycemic control. 


\section{Methodology}

This study is a cross-sectional study approved by the local ethical committee of Ain Shams University and registered in the Clinical Trials Government (NCT04531111). The participants were patients with type 1 diabetes and/or their caregivers. Children and adolescents with type 1 diabetes, less than 18 years, were recruited from Pediatrics and Adolescents Diabetes Unit (PADU), Pediatrics Hospital, Ain Shams University.

This study was conducted through an online questionnaire; however, for patients with limited internet access, the questionnaire was carried out through phone calls (according to patients' convenience).

Initially, the questionnaire was circulated among 200 patients with type 1 diabetes, yet 50 patients were not willing to either complete the questionnaire or were not willing to share their data. The remaining 150 questionnaire forms were evaluated, 16 forms were excluded because patients had associated comorbidities, and additional 19 forms were excluded as well because forms were not completed with missing responses.

The questionnaire included four main domains as well as reporting $\mathrm{HbA} 1 \mathrm{c}$ levels before and after lockdown. $\mathrm{HbA} 1 \mathrm{C}$ before and after lockdown was assessed using the same methodology "cation exchange high performance Liquid chromatography (CE-HPLC)". The first domain included demographic data and disease history of the patient. The second evaluated the dietary habits, diabetes care, and lifestyle before and after lockdown. The third reviewed the insulin regimen and requirements together with frequency of hypoglycemia and hyperglycemia before and after lockdown, and finally, the last domain evaluated mainly the COVID-19-related worries among patients as well as the communications channels with health professionals.

Perceived stress scale-10 (PSS-10) (Arabic Validated version) was used (with permission) to measure patients'/ caregivers' level of stress in response to the extraordinary status of the pandemic and its consequences. It is a 10-questions scale that was part of the questionnaire [8, 9]. Individual scores on the PSS can range from 0 to 40 with higher scores indicating higher perceived stress. Scores ranging from 0 to 13 were considered low stress, from 14 to 26 were considered moderate stress, and from 27 to 40 were considered high perceived stress.

\section{Statistical methods}

Analysis of data was done using Statistical Program for Social Science version 23 (SPSS Inc., Chicago, IL, USA). Continuous variables are presented either as mean \pm SD or median and interquartile range (IQR). Categorical variables are presented as percentages. For comparing variables before and after lockdown, the two-tail paired Student's $t$ test was performed. Categorical variables were compared using Chi square $\left(\mathrm{X}^{2}\right)$ test. Pearson correlation coefficients were used to assess the association between two normally distributed variables. Statistical significance was accepted when $\mathrm{p}<0.05$.

\section{Results}

A total of 115 patients responded to the questionnaire. About $60 \%$ of responders had either or both parents with a college or university degree. Almost $95 \%$ was on multiple daily injections (MDI), and only $5 \%$ was on continuous subcutaneous insulin infusion (CSII). Only $47 \%$ was on carb counting. Sixteen patients $(13.9 \%)$ were using flash glucose monitoring system (IsCGMs), and the rest were on regular self-monitoring of blood sugar (SMBG) (Supplemental Table).

During lockdown, diet control and eating habits were reported as worse in almost $60 \%$ of patients. Similar to diet control, overall diabetes control was worse during the lockdown in almost $59 \%$ of patients. Only $40 \%$ tended to do SMBG at least five times daily. Fluctuation of blood sugar with attacks of hyperglycemia and hypoglycemia was reported more frequently in $66 \%$ and $59 \%$, respectively. With lockdown and poor dietary habits, there was an increase in insulin dose $(61.7 \%)$. HbA1C, a surrogate marker of diabetes control, was reported as better in only one-third of patients, while the rest had worsening of their HbA1C (Fig. 1A). HbA1C significantly increased after the lockdown $(\mathrm{p}<0.001)$ with a percentage increment of $6.85 \pm 1.67 \%$ (Fig. 1B). Subset analysis showed that HbA1c improved in patients aged less than 5 years with a percentage decrement of $4.43 \pm 1.469$, yet this change was not significant. Unlike younger patients, patients aged 5-10 years and adolescents showed significantly increased HbA1C after lockdown with percentage increment of $8.6 \pm 1.484$ and $7.43 \pm 0.748$, respectively (Table 1 ).

The questionnaire revealed that only $18 \%$ of patients were enrolled in sports and only $5 \%$ continued to perform household exercises during lockdown (Supplemental Table).

Regarding communication with healthcare professionals, most patients and families were able to continue 
A

\section{Patterns of changes in $\mathrm{HbAlc}$}

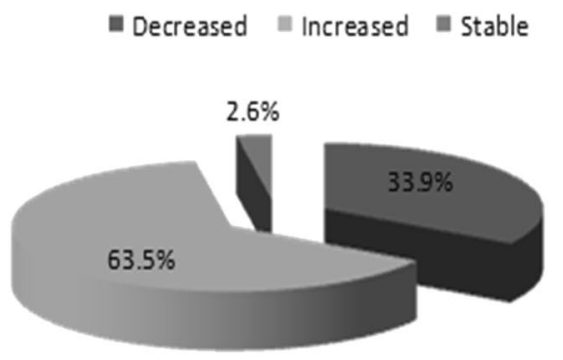

Fig. 1 Patterns of changes in HbA1C among the studied cohort during the lockdown period. During the period of lockdown, about $64 \%$ of patients showed an increase in the level of HbA1C, HbA1C was decreased in $34 \%$, and it was unchanged in about $3 \%$ (A). The

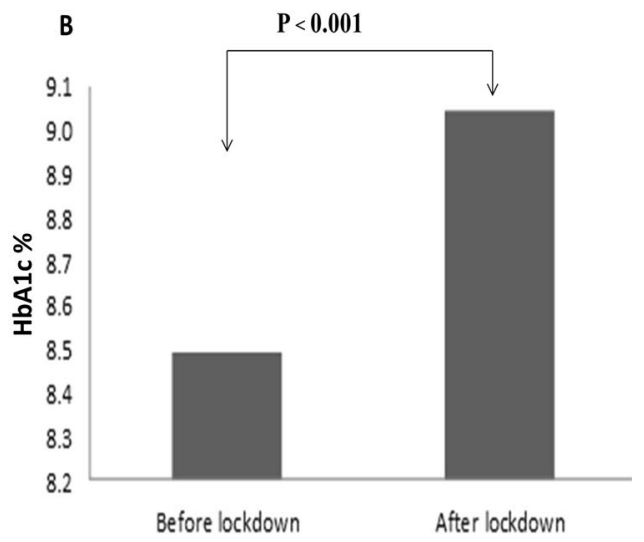

mean $\mathrm{HbA1C}$ significantly increased after lockdown $(\mathbf{B})$. The HbA1c before lockdown ranged from 6.2 to $12 \%$ (44-108) with a mean of $8.49 \pm 1.26 \%$ (69) compared to $\mathrm{HbA1C}$ ranging from 5.8 to $14 \%$ ( 40 $130)$ after lockdown with an average of $9.04 \pm 1.84 \%(75)(\mathrm{p}<0.001)$
Table 1 Effect of lockdown on HbA1C among different age groups

\begin{tabular}{llllll}
\hline & \multicolumn{2}{l}{ HbA1C\% (IFCC) } & \% change & p value & Sig \\
\cline { 2 - 3 } & Before lockdown & After lockdown & & & \\
\hline Age 0-5 years & $8.55 \pm 1.33(70)$ & $8.08 \pm 1.22(65)$ & $-4.43 \pm 1.47$ & 0.280 & NS \\
Age 5-10 years & $8.26 \pm 1.23(67)$ & $8.94 \pm 1.64(74)$ & $8.6 \pm 1.5$ & 0.001 & HS \\
Age 10-18 years & $8.65 \pm 1.27(71)$ & $9.28 \pm 2.01(78)$ & $7.43 \pm 1.8$ & 0.003 & HS \\
\hline
\end{tabular}

follow-up through a synchronous simple telemedicine service (real-time telephone or social media applications). However, with this facility still around, $3 \%$ failed to communicate (Supplemental Table).

Table 2 summarizes the demographic data and diabetes management among different age groups. Data showed that almost $70 \%$ of patients less than 5 years monitored blood glucose at least 5 times/day $(\mathrm{p}<0.05)$. There were significant differences in the pattern of diabetes control among different age groups. Patients aged 5-10 years and older patients tended to show worse control $(\mathrm{p}<0.01)$.

When evaluating the impact of duration of diabetes, eating habits and overall diabetes control during lockdown period was the worst among patients with diabetes duration of 1-5 years with more significant attacks of hypoglycemia and hyperglycemia (Fig. 2).

The COVID-19-related worries among the studied cohort were mainly the fear to catch SARs-COV2 infection, fear from getting admitted with any diabetes-related complication, and finally from shortage of medical supplies (Supplemental Table).

On analyzing the PSS-10, almost $76 \%$ showed moderate stress. A significant positive correlation was found between $\mathrm{HbA} 1 \mathrm{C}$ both before and after lockdown $(\mathrm{p}<0.05)$ (Fig. 3). Severe stress was more evident among caregivers of infants and toddlers with diabetes (Table 2).

\section{Discussion}

Patients with chronic conditions including diabetes experienced challenges during the period of lockdown especially patients in developing countries with pronounced barriers in accessing healthcare services and medical supplies [3].

To achieve tight control, monitoring of blood sugar all over the day in children with type 1 diabetes is mandatory; meanwhile, those with fluctuating blood sugar or intermittent hypoglycemia, blood glucose should be checked at least four times a day with additional check in case of signs or symptoms of occurring hypoglycemia [10].

It is obvious from the current study that about $51 \%$ of the patients monitored their blood glucose less frequent during the lockdown period with $60 \%$ of patients monitoring less than three times daily. The defect in SMBG could be related to shortage of supply or lack of insurance as most supplies are covered by insurance. This negative impact of lockdown was also reported in a similar study in Middle East where a higher percentage of families (43\%) had to ration or cut down the use of glucose test strips which led to more frequent hypo-/hyperglycemic excursions in glucose levels in most of their children [11].

When the lockdown was eased early in July, most patients were able to check their $\mathrm{HbA} 1 \mathrm{C}$, and there was 
Table 2 Demographic data and diabetes management among different age groups

\begin{tabular}{|c|c|c|c|c|c|c|}
\hline & \multirow{2}{*}{$\begin{array}{l}\text { Age } 0-5 \text { years } \\
\text { No. }=10\end{array}$} & \multicolumn{2}{|c|}{ Age $5-10$ years } & \multirow{2}{*}{$\begin{array}{l}\text { Age } 10-18 \text { years } \\
\text { No. }=61\end{array}$} & \multirow{2}{*}{$\mathrm{p}$ value } \\
\hline & & & No. $=44$ & & & \\
\hline \multirow[t]{3}{*}{ Duration of diabetes } & 6 months -1 year & $7(70.0 \%)$ & $9(20.5 \%)$ & & $4(6.6 \%)$ & 0.000 \\
\hline & $1-5$ years & $3(30.0 \%)$ & $30(68.2 \%)$ & & $20(32.8 \%)$ & \\
\hline & $>5$ years & $0(0.0 \%)$ & $5(11.4 \%)$ & & $37(60.7 \%)$ & \\
\hline \multirow[t]{2}{*}{ Gender } & Male & $6(60.0 \%)$ & $21(47.7 \%)$ & & $26(42.6 \%)$ & 0.571 \\
\hline & Female & $4(40.0 \%)$ & $23(52.3 \%)$ & & $35(57.4 \%)$ & \\
\hline \multirow[t]{2}{*}{ Insulin regimen } & Multiple daily injections & $8(80.0 \%)$ & $43(97.7 \%)$ & $58(95.1 \%)$ & & 0.074 \\
\hline & Insulin pump & $2(20.0 \%)$ & $1(2.3 \%)$ & $3(4.9 \%)$ & & \\
\hline \multirow[t]{3}{*}{ Number of daily injection of insulin } & Less than 3 times/day & $0(0.0 \%)$ & $0(0.0 \%)$ & $0(0.0 \%)$ & & 0.123 \\
\hline & 3 times/day & $0(0.0 \%)$ & $9(20.5 \%)$ & $6(9.8 \%)$ & & \\
\hline & More than 3 times/day & $10(100.0 \%)$ & $35(79.5 \%)$ & $55(90.2 \%)$ & & \\
\hline \multirow{3}{*}{$\begin{array}{l}\text { Eating habits and diet control during } \\
\text { lockdown }\end{array}$} & Same & $5(50.0 \%)$ & $11(25.0 \%)$ & $13(21.3 \%)$ & & 0.325 \\
\hline & Better & $0(0.0 \%)$ & $7(15.9 \%)$ & $10(16.4 \%)$ & & \\
\hline & Worse & $5(50.0 \%)$ & $26(59.1 \%)$ & $38(62.3 \%)$ & & \\
\hline \multirow{3}{*}{$\begin{array}{l}\text { Frequency of daily SMBG } \uparrow \text { during } \\
\text { lockdown }\end{array}$} & Less than 3 times/day & $3(30.0 \%)$ & $10(22.7 \%)$ & $21(34.4 \%)$ & & 0.048 \\
\hline & 3-4 times/day & $0(0.0 \%)$ & $19(43.2 \%)$ & $16(26.2 \%)$ & & \\
\hline & 5-7 times/day & $7(70.0 \%)$ & $15(34.1 \%)$ & $24(39.3 \%)$ & & \\
\hline \multirow[t]{3}{*}{ Diabetes control during lockdown } & Same & $7(70.0 \%)$ & $9(20.5 \%)$ & $11(18.0 \%)$ & & 0.008 \\
\hline & Better & $0(0.0 \%)$ & $8(18.2 \%)$ & $12(19.7 \%)$ & & \\
\hline & Worse & $3(30.0 \%)$ & $27(61.4 \%)$ & $38(62.3 \%)$ & & \\
\hline \multirow{2}{*}{$\begin{array}{l}\text { Hyperglycemia more often after the } \\
\text { lockdown }\end{array}$} & No & $5(50.0 \%)$ & $16(36.4 \%)$ & $18(29.5 \%)$ & & 0.406 \\
\hline & Yes & $5(50.0 \%)$ & $28(63.6 \%)$ & $43(70.5 \%)$ & & \\
\hline \multirow{2}{*}{$\begin{array}{l}\text { Hypoglycemia more often after the } \\
\text { lockdown }\end{array}$} & No & $4(40.0 \%)$ & $16(36.4 \%)$ & $27(44.3 \%)$ & & 0.718 \\
\hline & Yes & $6(60.0 \%)$ & $28(63.6 \%)$ & $34(55.7 \%)$ & & \\
\hline \multirow[t]{2}{*}{ Exercise before lockdown } & No & $9(90.0 \%)$ & $37(84.1 \%)$ & $51(83.6 \%)$ & & 0.874 \\
\hline & Yes & $1(10.0 \%)$ & $7(15.9 \%)$ & $10(16.4 \%)$ & & \\
\hline \multirow[t]{2}{*}{ Exercise during lockdown } & No & $10(100.0 \%)$ & $41(93.2 \%)$ & $59(96.7 \%)$ & & 0.531 \\
\hline & Yes & $0(0.0 \%)$ & $3(6.8 \%)$ & $2(3.3 \%)$ & & \\
\hline \multirow[t]{4}{*}{ Method of communication } & Physical visit & $0(0.0 \%)$ & $3(6.8 \%)$ & $5(8.2 \%)$ & & 0.159 \\
\hline & Phone call & $8(80.0 \%)$ & $20(45.5 \%)$ & $19(31.1 \%)$ & & \\
\hline & Social media & $2(20.0 \%)$ & $20(45.5 \%)$ & $35(57.4 \%)$ & & \\
\hline & Couldn't communicate & $0(0.0 \%)$ & $1(2.3 \%)$ & $2(3.3 \%)$ & & \\
\hline \multirow[t]{3}{*}{ Satisfaction with communication } & Not satisfied & $0(0.0 \%)$ & $3(6.8 \%)$ & $8(13.1 \%)$ & & 0.860 \\
\hline & Mildly satisfied & $2(20.0 \%)$ & $7(15.9 \%)$ & $14(23.0 \%)$ & & \\
\hline & Satisfied & $8(80.0 \%)$ & $34(77.3 \%)$ & $39(63.9 \%)$ & & \\
\hline \multirow[t]{2}{*}{ Afraid about shortage of supply } & No & $1(10.0 \%)$ & $4(9.1 \%)$ & $14(23.0 \%)$ & & 0.142 \\
\hline & Yes & $9(90.0 \%)$ & $40(90.9 \%)$ & $47(77.0 \%)$ & & \\
\hline \multirow[t]{4}{*}{ COVID-19-related worries } & $\begin{array}{l}\text { Difficulty in contacting healthcare } \\
\text { physician }\end{array}$ & $1(10.0 \%)$ & $1(2.3 \%)$ & $1(1.6 \%)$ & & 0.69 \\
\hline & $\begin{array}{l}\text { Afraid of not finding the medical } \\
\text { care if infected with COVID-19 }\end{array}$ & $1(10.0 \%)$ & $5(11.4 \%)$ & $12(19.7 \%)$ & & \\
\hline & $\begin{array}{l}\text { Feeling more susceptible to infec- } \\
\text { tion }\end{array}$ & $3(30.0 \%)$ & $13(29.5 \%)$ & $17(27.9 \%)$ & & \\
\hline & Fear of hospital admission & $5(50.0 \%)$ & $25(56.8 \%)$ & $31(50.8 \%)$ & & \\
\hline \multirow[t]{2}{*}{ PSS-10 } & Moderate stress & $4(40.0 \%)$ & $35(79.5 \%)$ & $49(80.3 \%)$ & & 0.017 \\
\hline & High perceived stress & $6(60.0 \%)$ & $9(20.5 \%)$ & $12(19.7 \%)$ & & \\
\hline
\end{tabular}

${ }^{\dagger} S M B G$ self-monitoring of blood glucose, $\diamond$ PSS-10 perceived stress scale-10 

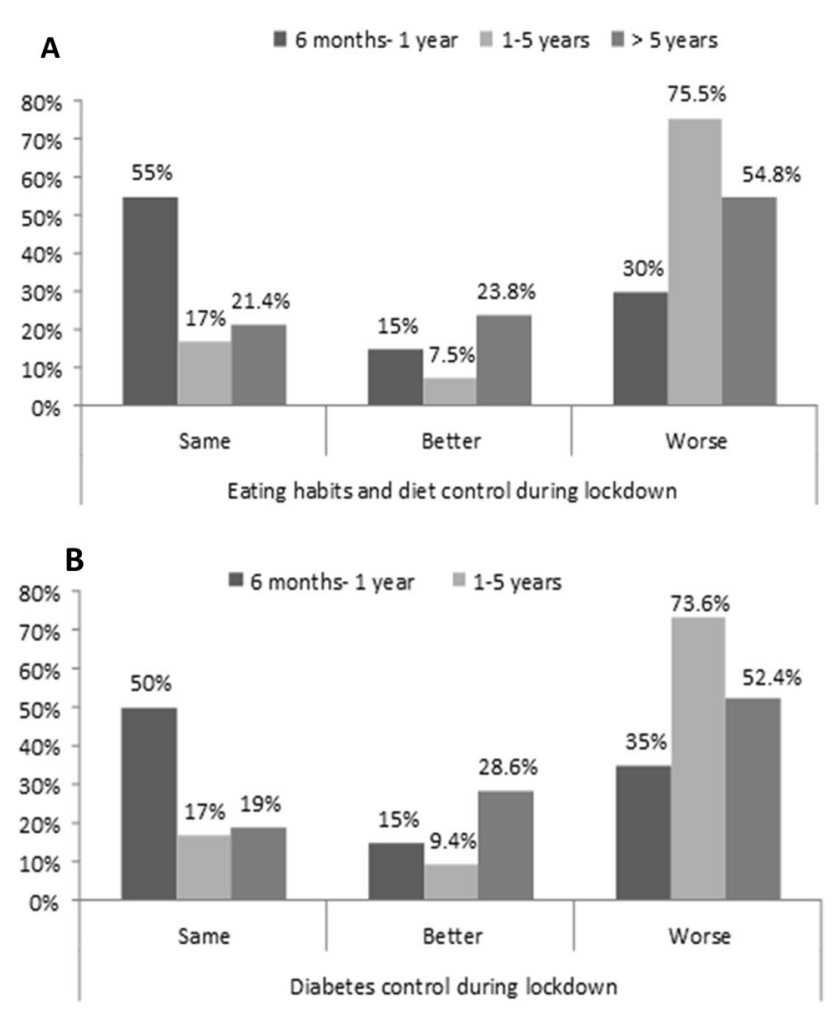

Fig. 2 Eating habits and overall diabetes control during lockdown period among patients with different duration of diabetes. Eating habits (A) and overall diabetes control (B), during lockdown period, were the worst among patients with diabetes duration of 1-5 years $(\mathrm{p}<0.05)$

an overall significant increase in mean $\mathrm{HbA} 1 \mathrm{C}$. Although being non-significant, HbA1C improved in toddlers and preschoolers; however, school children and adolescents had significant worsening. This is similar to previous studies which showed that the pandemic and lockdown negatively impacted the metabolic control of type 1 diabetes among children and adolescents [11-13]. However, data from the current study, regarding impact of lockdown on glycemic control, was in contrast to data explored by previous studies showing no worsening or even improvement of glycemic control during the period of lockdown [5-7].
Differences in study population as well as differences in standards of care together with differences in availability of medical supply could provide insight and possible explanation for such observed difference.

In concordance with a study conducted among an Indian cohort, a country with limited resources as ours, poor dietary habits and lack of physical exercise are noticeable causes of the poor glycemic control during the period of lockdown [13].

Limited outdoor activities, with increased desire for frequent snacking especially with online learning, had made it noticeable that dietary habits and control were becoming worse among almost all age groups; however, those with newly diagnosed diabetes or duration less than a year were the best in regard to maintaining diet control in comparison to those with longer duration. We speculated that parents or caregivers of patients, whose disease duration is less than a year, took over diabetes control all over the day, which may partially explain the relative improvement in dietary habits. Similarly, Shah et al. highlighted the importance of family support in maintaining a steady daily routine [14].

The pandemic impacted the practice and the standard of care offered to patients with type 1 diabetes and the implementation of telemedicine service, which became a crucial tool in managing patients $[15,16]$.

With the onset of lockdown, our diabetes team started to launch a telemedicine service. Synchronous simple service was used by sharing logbooks and patients' inquiries through social media applications (WhatsApp and Facebook) and phone calls. Around $97 \%$ of the patients and their families were successfully able to communicate with their medical team, and almost $70 \%$ were more or less satisfied. Similar data from a Jordanian study showed the efficacy of simple basic ways of telemedicine service in managing type 1 diabetes through sharing data from logbooks and adjusting insulin regimens [11].

This survey explored the worries associated with COVID19 among the studied cohort and showed that the pandemic was associated with different worries among patients with diabetes. Almost half was afraid from hospital admission and contacting infection, and about $29 \%$ was feeling more
Fig. 3 Correlation between PSS -10 and $\mathrm{HbA} 1 \mathrm{C}$ before and after lockdown. A significant positive correlation was noticed between PSS-10 and glycemic control, as reflected by $\mathrm{HbA} 1 \mathrm{C}$ before (A) and after lockdown (B) $(\mathrm{p}<0.001)$
A

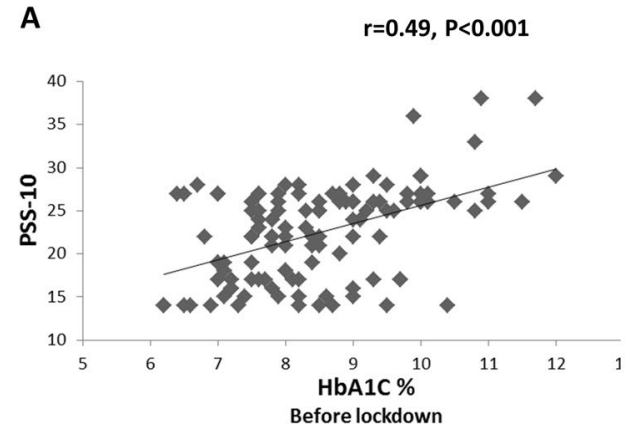

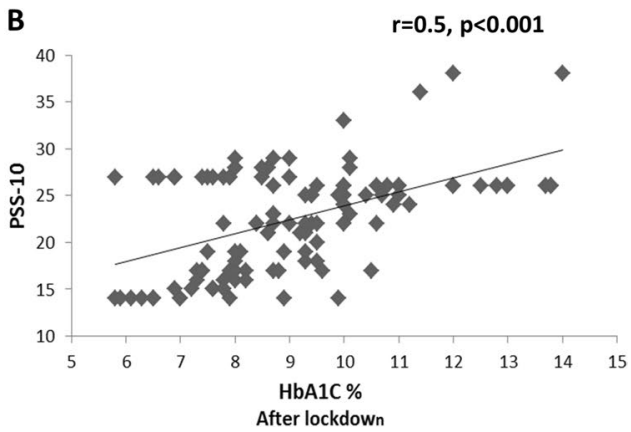


susceptible to infection. Beside the previous worries, the majority was afraid of shortage of medical supplies.

Joensen and colleagues showed that their studied cohort was most frequently worried about COVID-19, $56 \%$ was worried of being severely affected due to diabetes, $28 \%$ was afraid of being unable to manage diabetes if infected with COVID-19, and $24 \%$ was worried from lack of medical supplies [17]. In this context, different resources and diabetes fact sheets were developed aiming to support and manage patients' worries and concerns about COVID-19 [18-20].

The current study evaluated the levels of perceived stress among patients and/or caregivers during the challenging period of lockdown. Sixty percent perceived moderate stress, and $40 \%$ perceived severe stress. This was shown in a similar study where more than half of the studied cohort reported moderate stress [12].

Several studies evaluated perceived stress among patients with diabetes and correlated it with patients' glycemic control. Diabetes treatment, management and perception of complications anticipated by poorly controlled patients significantly impact patients' perception of stress [21, 22]. A significant positive correction was noticed between PSS-10 and pre-lockdown $\mathrm{Hb} \mathrm{A} 1 \mathrm{C}$. Similar finding was reported by Agarwal et al., where they observed higher PSS-10 scores among adolescent patients with poor glycemic control. They attributed such observation to the fact that the pandemic could possibly augment pre-existing health-related stress [12].

Similar to the findings reported by Agarwal et al. [12], we observed a significantly positive correlation between level of perceived stress and patients' glycemic control, as reflected by $\mathrm{Hb} \mathrm{A} 1 \mathrm{C}$ level assessed after ease of lockdown. Stress is known to negatively impact outcome of disease, and this could be related to non-adherence to medication and disruption of healthy lifestyle as well [23].

The pandemic affected all aspects of life with special impact on patients with type 1 diabetes. The main limitation of the current study is relatively small sample size representing data from a single center. The absence of data assessing the history of COVID-19 infection in patients/caregivers as well as contact with suspected or confirmed cases is another limitation of the current study. Additionally, the disadvantages associated with the nature of online survey with its potential have limited the ability to access certain portals.

\section{Conclusion}

The pandemic had a significantly negative impact on glycemic control among Egyptian children and adolescents with type 1 diabetes. The restriction of mobility due to the lockdown created barriers in assessing health team and continuity of healthcare, all of which highlighted the importance of initiating a telemedicine service. The limited availability and the fear of shortage of medical supply forced the patients to ration glucose monitoring. The lockdown affected patients/ caregivers perception of stress and initiated a set of COVID19 worries.

Supplementary Information The online version contains supplementary material available at https://doi.org/10.1007/s13410-021-00968-y.

Author contribution Both Dr. Elhenawy and Dr. Eltonbary shared in designing the study, carried out the practical part of the study, drafted, reviewed, and revised the manuscript. Both authors approved the final manuscript as submitted and agree to be accountable for all aspects of the work.

Data availability N/A

Code availability N/A

\section{Compliance with ethical standards}

Ethical approval The study was approved by the local ethical committee of Ain Shams University and registered in the Clinical Trials Government (NCT04531111).

Consent to participate N/A

Consent for publication N/A

Conflict of interest The authors declare no competing interests.

\section{References}

1. World Health Organization. Coronavirus disease 2019 (COVID19): situation report 65. March 2020.https://www.who.int/docs/ defaultsource/coronaviruse/situation-reports/20200325-sitrep-65covid-19.pdf.

2. Wang C, Horby PW, Hayden FG, Gao GF. A novel coronavirus outbreak of global health concern. Lancet. 2020;395(10223):470 3. https://doi.org/10.1016/S0140-6736(20)30185-9.

3. Saqib MAN, Siddiqui S, Qasim M, Jamil MA, Rafique I, Awan UA, et al. Effect of COVID 19 lockdown on patients with chronic diseases. Diabetes Metab Syndr. 2020;14(6):1621-3. https://doi. org/10.1016/j.dsx.2020.08.028.

4. Di Renzo L, Gualtieri P, Pivari F, Soldati L, Attinà A, Cinelli G, et al. Eating habits and lifestyle changes during COVID-19 lockdown: an Italian survey. J Transl Med. 2020;18(1):229. https:// doi.org/10.1186/s12967-020-02399-5.

5. Tornese G, Ceconi V, Monasta L, Carletti C, Faleschini E, Barbi E. Glycemic control in type 1 diabetes mellitus during COVID19 quarantine and the role of in-home physical activity. Diabetes Technol Ther. 2020;22(6):462-7. https://doi.org/10.1089/dia. 2020.0169 .

6. Bonora BM, Boscari F, Avogaro A, Bruttomesso D, Fadini GP. Glycaemic control among people with type 1 diabetes during lockdown for the SARS-CoV-2 outbreak in Italy. Diabetes Ther. 2020;11(6):1-11. https://doi.org/10.1007/s13300-020-00829-7.

7. Di Dalmazi G, Maltoni G, Bongiorno C, Tucci L, Di Natale V, Moscatiello S, et al. Comparison of the effects of lockdown due to COVID-19 on glucose patterns among children, adolescents, 
and adults with type 1 diabetes: CGM study. BMJ Open Diabetes Res Care. 2020;8(2):001664.

8. Cohen S, Kamarck T, Mermelstein R. A global measure of perceived stress. J Health Soc Behav. 1983;24(4):385-96.

9. Chaaya M, Osman H, Naassan G, Mahfoud Z. Validation of the Arabic version of the Cohen perceived stress scale (PSS10) among pregnant and postpartum women. BMC Psychiatry. 2010;15(10):111. https://doi.org/10.1186/1471-244X-10-111.

10. Banerjee M, Chakraborty S, Pal R. Diabetes self-management amid COVID-19 pandemic. Diabetes Metab Syndr. 2020;14(4):351-4. https://doi.org/10.1016/j.dsx.2020.04.013.

11. Odeh R, Gharaibeh L, Daher A, Kussad S, Alassaf A. Caring for a child with type 1 diabetes during COVID-19 lockdown in a developing country: challenges and parents' perspectives on the use of telemedicine. Diabetes Res Clin Pract. 2020;168: 108393. https://doi.org/10.1016/j.diabres.2020.108393.

12. Agarwal N, Harikar M, Shukla R, Bajpai A. COVID-19 pandemic: a double trouble for Indian adolescents and young adults living with type 1 diabetes. Int J Diabetes Dev Ctries. 2020;18:1-7. https://doi.org/10.1007/s13410-020-00869-6.

13. Verma A, Rajput R, Verma S, Balania VKB, Jangra B. Impact of lockdown in COVID 19 on glycemic control in patients with type 1 diabetes mellitus. Diabetes Metab Syndr. 2020;14(5):1213-6. https://doi.org/10.1016/j.dsx.2020.07.016.

14. Shah N, Karguppikar M, Bhor S, Ladkat D, Khadilkar V, Khadilkar A. Impact of lockdown for COVID-19 pandemic in Indian children and youth with type 1 diabetes from different socio-economic classes. J Pediatr Endocrinol Metab. 2020. https://doi.org/ 10.1515/jpem-2020-0460.

15. Castle JR, Rocha L, Ahmann A. How COVID-19 rapidly transformed clinical practice at the Harold Schnitzer diabetes health center now and for the future. J Diabetes Sci Technol. 2020. https://doi.org/10.1177/1932296820929368.

16. Danne T, Limbert C. COVID-19, type 1 diabetes, and technology: why paediatric patients are leading the way. Lancet Diabetes Endocrinol. 2020. https://doi.org/10.1016/s2213-8587(20) 30155-8.
17. Joensen LE, Madsen KP, Holm L, Nielsen KA, Rod MH, Petersen AA, et al. Diabetes and COVID-19: psychosocial consequences of the COVID-19 pandemic in people with diabetes in Denmarkwhat characterizes people with high levels of COVID-19-related worries? Diabet Med. 2020;37(7):1146-54. https://doi.org/10. 1111/dme.14319.

18. Stewart R, Augarde S. Managing worry about COVID-19 and diabetes. Available at https://www.t1resources.uk/fileadmin/user_ upload/downloads/Coronavirus/Managing_worry_about_covid19_and_type_1_diabetes_print_version.pdf. Last accessed 29 Apr 2020 .

19. National Diabetes Services Scheme. Managing worry about COVID-19 and diabetes fact sheet. Canberra: NDSS, 2020. Available at https://www.ndss.com.au/about-diabetes/resources/find-aresource/managing-worry-about-covid19-fact-sheet/Last accessed 29 Apr 2020.

20. Diabetes Australia. COVID-19 diabetes healthy. Available at https://www.diabetesaustralia.com.au/diabetes-healthy Last accessed 29 Apr 2020.

21. Kelly SJ, Ismail M. Stress and type 2 diabetes: a review of how stress contributes to the development of type 2 diabetes. Annu Rev Public Health. 2015;36:441-62.

22. Mishra A, Podder V, Modgil S, Khosla R, Anand A, Nagarathna $\mathrm{R}$, et al. Higher perceived stress and poor glycemic changes in prediabetics and diabetics among indian population. J Med Life. 2020;13(2):132-7. https://doi.org/10.25122/jml-2019-0055.

23. Cohen DM, Lumley MA, Naar-King S, Partridge T, Cakan N. Child behavior problems and family functioning as predictors of adherence and glycemic control in economically disadvantaged children with type 1 diabetes: a prospective study. J Pediatr Psychol. 2004;29(3):171-84. https://doi.org/10.1093/jpepsy/jsh019.

Publisher's note Springer Nature remains neutral with regard to jurisdictional claims in published maps and institutional affiliations. 